\title{
Visiones del Caravaggio romano entre las páginas de Carlo Emilio Gadda
}

\author{
Linda Garosi • \\ Universidad de Córdoba (España)
}

\begin{abstract}
Resumen
Desde sus comienzos literarios Gadda entabla un interesante diálogo con la obra figurativa de Caravaggio. En sus cuadros el autor halla una poderosa fuente de inspiración para el desarrollo de un proyecto narrativo que pretende indagar en lo real. Al mismo tiempo asimila elementos iconográficos y formales a los que amolda su escritura creativa. A la Vocación de San Mateo y a la Conversión de San Pablo el escritor hace alusiones en sus escritos teóricos donde, además, traza sus representaciones literarias. Tanto los cuadros como estas reelaboraciones ecfrásticas constituyen, a su vez, unos intertextos fundamentales de las novelas de Gadda para la construcción de escenas cargadas de intensidad expresiva.
\end{abstract}

Palabras clave:

Gadda · pintura · Caravaggio · novela italiana contemporánea

\begin{abstract}
From his very literary beginning, Gadda starts an interesting dialogue with Caravaggio's figurative works. In his paintings, the authos finds a powerful source of inspiration in order to carry out a narrative design which aims to enquire into the reality. Meanwhile he gets from it both iconographic and stylistic elements that shape his prose. The author mentions either The Calling of St. Matthew and The Conversion of St. Paul in his theoric writings where, in addition to that, he draws verbal descriptions of them. These paintings as well as their literary representations are essential intertexts of Gadda's novels in the construction of images with an expressive strenght.
\end{abstract}

\section{Key words:}

· Gadda · painting · Caravaggio · contemporary Italian novel

\footnotetext{
- Linda Garosi es profesora contratada, doctora del Área de Filología Italiana de la Facultad de Filosofía y Letras de la Universidad de Córdoba (España). Licenciada por la Universidad de Verona en el 2000, consigue el título de Doctora en 2006, con una beca ministerial de Formación del Profesorado Universitario del Ministerio de Educación de España. En 2009 publica la monografía Novela y personaje en el ocaso del fin de siglo (XIX$X X)$. Estudio comparativo de la narrativa italiana y española. En sus publicaciones y ponencias en congresos se ha ocupado de D'Annunzio, Pirandello, Salvatore Quasimodo, Carlo Dossi, Carlo Emilio Gadda, entre otros.
} 
El interés por la obra de Caravaggio constituye una constante que vertebra el sistema poético e imaginativo de Carlo Emilio Gadda. Si uniéramos entre sí las alusiones al pintor o las reiteraciones icónicas dispersas en sus escritos, obtendríamos una línea que los une y que está perfectamente delineada desde fecha temprana. Es importante señalar este dato a los fines del presente trabajo. Además con ello se hace hincapié en la presencia activa de una determinada matriz figurativa en la fase fundacional del proyecto narrativo de Gadda. En efecto, es justamente en la nota compositiva de la «riesumazione manzoniana", elaborada al margen de la primera e inacabada novela Racconto di ignoto letterario del Novecento (1924-1925), luego confluida en "Apologia manzoniana» (1927), donde al evocar la célebre Vocación de San Mateo (1599-1600) el aspirante novelista deja patente la intensa impresión recibida por el cuadro así como su habilidad por leer la imagen pictórica y su pericia para identificar los componentes figurativos y los procedimientos técnicos que la configuran. Como se verá en el cotejo entre los fragmentos del texto citado y la obra de Caravaggio a la que se refieren, Gadda compone una descripción de la escena pintada que es preciso tomar en consideración al hilo del presente trabajo, no sólo porque trasluce su original lectura de la lección del pintor a través del binomio Manzoni-Caravaggio, ${ }^{1}$ sino, y sobre todo, por las interpolaciones entre escritura creativa y pintura. Análogo procedimiento compositivo se halla, unos años más tarde, en el artículo «Il pasticciaccio» (Letteratura, 1957). El cuadro al que se hace referencia esta vez es la Conversión de San Pablo (1601-1602). En ambos casos, Gadda decodifica los lienzos de Caravaggio y los vuelve a codificar mediante la palabra obteniendo unos fragmentos de naturaleza ecfrástica que incorpora al fluir de sus reflexiones y que permanecerán firmemente arraigados en su imaginación. ${ }^{2}$ Se trata, por tanto, del punto de partida imprescindible para indagar en la intertextualidad existente entre la escritura del narrador y la obra del pintor (Raimondi, Lipparini). Es allí donde quedan plasmadas muestras de un repertorio iconográfico que aflorará, aun profundamente metamorfoseado, en la posterior producción narrativa de Gadda. A este respecto, en la segunda parte del presente trabajo, nos detendremos en el análisis de unas secuencias que, engarzadas en las páginas del Aprendizaje del dolor (título original, La cognizione del dolore, 1938-1941), ${ }^{3}$ desprenden a los ojos del lector un intenso dramatismo logrado también gracias a composiciones de la escena, a posturas de los personajes actantes, a juegos de claroscuro, para los que la pluma calca al pincel.

En los primeros años veinte, el escritor milanés era un ingeniero de unos treinta años que acababa de tomar una decisión importante: dedicarse a la narrativa y escribir su primera, y desesperada, novela. En la primavera de 1924, tras su regreso a Italia 
de América del Sur, empieza a componer, intercalando anotaciones, fragmentos narrativos y consideraciones teóricas, una obra que llevaría como título Racconto italiano di ignoto del Novecento con la intención de optar al «Premio Mondadori» en la categoría de novela inédita. Pasado el impulso producido por el aliciente externo, el escritor siguió trabajando en su experimento literario que, pese a no proporcionarle la notoriedad deseada (de hecho se publicó póstumo en 1983), le llevó a madurar un personal programa poético con importantes imbricaciones epistemológicas, tal y como se trasluce años más tarde en su Meditazione milanese (1928). ${ }^{4}$ En ambos se encuentran menciones directas al artista y a su obra. Al margen de este último ensayo literario-filosófico se halla una breve apostilla en la que Gadda confesaba que delante de los cuadros del gran pintor lombardo sentía "un'ebbrezza mista a gratitudine» (una mezcla de exaltación y agradecimiento). Por otro lado, que la admiración implicara una afinidad de valores artísticos íntimamente percibida queda corroborado por la «bizzarra» dedicatoria que debería haber aparecido en el umbral paratextual de Racconto: «al mio grande ed inarrivabile maestro Michelangelo Amorigi da Caravaggio" [a mi grande e inalcanzable maestro Michelangelo Amorigi de Caravaggio]. ${ }^{5}$ A este respecto, y antes de introducir el objeto de estudio, es útil bosquejar brevemente las razones intrínsecas así como el trasfondo del diálogo tan precozmente entablado con el pintor. Es preciso recordar, entonces, que Gadda nombra a Caravaggio por primera vez en su original tránsito a través de la obra maestra de Alessandro Manzoni, los Novios (título original, Promessi Sposi) (Raimondi, Contini). Como se ha dicho, el nombre del artista aparece en la nota compositiva a Racconto, la conocida «riesumazione manzoniana» fechada $4 \mathrm{de}$ agosto de 1924, que luego apareció autónomamente en una versión más madura en el artículo titulado "Apologia manzoniana» publicado en la revista florentina Solaria en 1927. Ello es significativo puesto que, desde sus comienzos narrativos, "Gadda prende subito a interrogarsi sulla legittimità della forma romanzo, su come si possano raccontare e costruire gli eventi» (Raimondi:134) [Gadda comienza en seguida a plantearse si es legitima la forma novela y cómo se pueden relatar y construir los sucesos]. Con este fin busca unos modelos a seguir cuyas obras artísticas penetren en el «ingarbugliato intreccio» de orden y caos que presenta la realidad trágica y común, la sondeen y devuelvan una imagen que se revelará, al mismo tiempo, grotesca y severa. En su ensayo, Gadda subraya cómo Manzoni supo encontrar las soluciones formales adecuadas para "diseñar» uno de los momentos más trágicos de la historia del hombre: el siglo XVII. Hace especial hincapié, pues, en el efecto de «immediatezza» conseguido, por un lado, gracias al uso de un lenguaje plasmado a partir de la lengua hablada por los hombres de carne y hueso (sujetos histórico-sociales de todas las clases) y, por otro, gracias a los efectos figurativos que crean los pasajes descriptivos. Simultáneamente, al indicar en Caravaggio uno de los correspondientes pictóricos más significativos, al lado de los «tenui tocchi» del «Barocco lombardo» ${ }^{6}$ o de los «lividori» de «lo Spagnoletto», ${ }^{7}$ Gadda ofrece una clave de lectura inusual, en cuanto diametralmente opuesta a la tradicional interpretación de la obra maestra del milanés. ${ }^{8}$ Por otra parte, la peculiar síntesis llevada a cabo por Gadda se fundamentaba en la elección de Manzoni y Caravaggio en cuanto intérpretes privilegiados de un «realismo gnoseológico y satírico» que les permite hurgar en el magma de la existencia y de la historia, así como representar el mundo y a los hombres desvelando también su cara más atroz y anómala. Aún en 1957, en el ensayo con el que presenta la publicación en volumen de su gran 
novela romana el Zafarrancho, Gadda escribiría retomando con su consabido afán autoexegético este mismo planteamiento que, como se ha dicho, es crucial para el desarrollo de su proyecto: «e poi un problema estetico, ed etico, mi ha sempre scavato l'anima: a me, sì, che venni imputato di calligrafismo, di barocchismo. Qual è il grado di adesione interna, di accensione intima nei confronti del tema, che induce ad opera l'artista, che gli guida la mano sulla tela? Sì: la mano e il pennello? (2008:509) [y luego un problema estético, y ético, que nunca ha dejado de escarbar en mi alma: a mi, sí, que se me acusó de caligrafismo, de barroquismo. ¿Cuál es el grado de adhesión interna, de activación intima para con su tema, que instiga a obrar al artista, que le guia la mano sobre el lienzo? No hay duda: ¿la mano y el pincel?].

En la cita el escritor vuelve a insistir de nuevo al cabo de los años en una de las matrices figurativas imprescindibles en la configuración de su entramado narrativo; es decir, Caravaggio. Al mismo tiempo parece aludir a esa contaminación de códigos que, como parte integrante de su proceso creativo, ya había coagulado de forma ejemplar en la representación literaria de aquella "fulguración figurativa» de un Caravaggio manzoniano sugerida por la visión de la Vocación de San Mateo.

Tal y como ha puesto de relieve la crítica, aunque Gadda llegara a resultados muy personales en su proceso de interpretación seguía, sin embargo, unas tendencias que atravesaban unas áreas culturales comunes en el comienzo del siglo XX en Italia. En ámbito literario, se le reconocía a Manzoni, en el paso de Fermo y Lucia (1823) a Los Novios (1827), el papel de iniciador de la novela moderna italiana, además de ejemplar modelo de narrativa realista al que seguir en el contexto de una imperiosa necesidad de volver al orden tras la eclosión vanguardista y los formalismos finiseculares. ${ }^{9}$ Paralelamente, en el campo de las artes plásticas, se presencia el despertar de un interés generalizado por la pintura italiana de los siglos XVI y XVII en general, y por Caravaggio en particular. La primera manifestación que pone de relieve la atención por la pintura del Seicento data de 1922, cuando una comisión, presidida por Ugo Ojetti, reunió en el Palacio Pitti de Florencia más de mil obras que documentaban la Pittura italiana del Sei e Settecento. Esta muestra coronaba una serie de estudios que se habían comenzado en la segunda década del siglo XX, cuando «Michelangelo Merisi detto il Caravaggio» representaba un tema de vanguardia crítica del que se ocuparon, en primera instancia, Roberto Longhi y Lionello Venturi. Pese a ello, el empuje decisivo para el desarrollo de estos estudios vino del otro lado de los Alpes y reforzó el incipiente proceso de recuperación del arte barroco tras el juicio negativo de Benedetto Croce, permitiendo revelar detrás de la imagen monolítica del Manierismo y del Barroco una pluralidad de vertientes estilísticas. ${ }^{10}$ En este sentido, fue decisiva la contribución de Walter Friedländer, en cuanto "consideraba a Caravaggio, los Carracci, Cigoli y Cerano los padres de un Antimanieristische Stil um 1590, que, rechazando la artificiosidad y la complicación del manierismo, se volvía hacia la observación de la realidad, al hombre en sí y para sí, a su psicología y su expresividad» (Pacciarotti:8). Los frutos de esta trayectoria de estudios sobre el Seicento llegaron en la segunda posguerra, cuando Longhi pudo organizar la Mostra di Caravaggio e dei caravaggeschi en el Palazzo Reale de Milán en 1951 a la que siguió la publicación del catálogo monográfico, Caravaggio, que constituye un hito en la historiografía dedicada al pintor. La exposición de 1922 tuvo una gran repercusión a nivel nacional, por lo que pudo ser la ocasión externa que llevó Gadda a acercarse a la pintura de Caravaggio. Pese a que no se disponga de ninguna prueba concluyente, es razonable suponer que 
el aspirante a escritor tuviera ocasión de visitar la muestra florentina antes de su inminente viaje a Argentina (1922-1924) y allí pudo fijarse en las telas romanas de su coterráneo. Gianfranco Contini apoya en cambio la tesis de que Gadda se sirvió de reproducciones fotográficas para alimentar su imaginación antes de ser, como su célebre alter ego del Zafarrancho, el comendador Angeloni, "periodico visitatore, in ora chiara, della capella Contarelli a San Luigi de' Francesi a la Scrofa, dove le tre tele del Caravaggio sembrano vivere in un tempo sospeso» (Gadda, 2008:507) [visitante asiduo, durante el día, de la capilla Contarelli en San Luigi de' Francesi a la Scrofa, donde los tres lienzos de Caravaggio parecen vivir en un tiempo suspendido]. En efecto, en Racconto, la Vocación de San Mateo se cita desde la página de un libro alumbrada por un cono de luz:

Sulla tavola un cerchio luminoso, l'intersezione del cono di luce d'una lampada appesa: e dentro quel cerchio magico, delle carte e dei libri e uno aperto, con meravigliose figure. I margini si perdevano nel buio, quasi attingendo dal buio la potenza misteriosa della significazione e una figura alta e immota riceveva i raggi centrali del proiettore... Il Cristo del Caravaggio rivolgeva a Matteo un muto rimprovero, un muto ordine. E il viso del martire si illuminava di una tristezza tragica e di una gratitudine gioiosa, preludio terreno ai gaudi impensabili della vita vera. (2009:554-555)

[En la mesa un círculo luminoso, la intersección del cono de luz de una lámpara colgada: y dentro de aquel círculo mágico, unos papeles y unos libros, y uno de ellos abierto, con maravillosas figuras. Los márgenes se perdían en la oscuridad, casi como si de la oscuridad le viniera la potencia misteriosa de la significación y una figura alta e inmóvil recibia los rayos centrales del proyector... El Cristo del Caravaggio dirigía a Mateo un mudo reproche, una muda orden. Y el rostro del mártir se iluminaba de una tristeza trágica y de una gozosa alegría, preludio terrenal a los júbilos desconocidos de la vida verdadera]

Sin embargo, como sugiere Lipparini, aunque el escritor recurriera a una foto durante la escritura, el hecho de que Gadda hiciera alusión directa justamente a uno de los cuadros que constituyeron la verdadera revelación de la exposición florentina, ya que "per la prima volta, venivano riportati alla luce dalle tenebre che avvolgevano la cappella Contarelli» (1994:91) [por primera vez, se rescataban de las tinieblas que envolvían la capilla Contarelli y eran devueltos a la luz] lleva a suponer que, en la muestra de Palacio Pitti, Gadda pudo embeberse, gracias a la iluminación correcta, de la potencia expresiva emanada por la obra y guardar así un recuerdo visivo y emocional de ella que caló muy hondo.

En dos de sus textos teóricos, el autor menciona de forma directa los cuadros que, entre otros, tributaron mayor notoriedad a Caravaggio durante su periodo romano. Se trata de Vocación de San Mateo ${ }^{11}$ para la "Apologia manzoniana" (1927) y la Conversión de San Pablo ${ }^{12}$ para "Il pasticciaccio» (1957). Lo que interesa destacar en el cotejo entre el cuadro y su evocación literaria es la agudeza con la que Gadda descifra la imagen pictórica y la fija verbalmente. En "Apología» la descripción del cuadro logra vehicular no sólo la inmediatez de la visión del espectador, sino también el personal proceso interpretativo del mismo escritor tanto de los medios pictóricos empleados como del desenlace narrativo que sugiere la escena y, en última instancia, su significación (Figura 1). El motor de la acción, como reconoce Gadda con acierto, es la entrada en escena del Cristo que, acompañado por San Pedro, ordena con gesto perentorio a Mateo que lo siga. A este eje narrativo se le 
superpone, o tal vez contrapone, otro sugerido por la actitud desafiante de uno de los jóvenes compañeros de Mateo que, armado con espada, se presenta de espaldas ubicándose en el centro de la composición y en primer plano. Desde un punto de vista sintáctico la contemporaneidad de las dos acciones queda expresada por el nexo «mientras» y con ello la suspensión de la acción que se crea en el instante mismo en el que aparece la divinidad:

Mentre il Cristo comanda a Matteo che lo segua, un viso adolescente, sensualmente distratto, chiede: "Chi cerca costui?». Il vino imporpora le su floride gote ed egli si volge indifferente, con un sorrisetto quasi bolognese. Una bella piuma ha nel cappello di velluto violetto e una sottile spada al fianco. Le gambe nervose si vedono di là dallo sgabello, come in riposo, dopo l'accorrere, dopo il rissare. (2008:681)

[Mientras el Cristo ordena a Mateo que lo sigua, un rostro de adolescente, sensualmente distraido, pregunta: “¿A quién busca éste?». El vino enrojece sus lozanas mejillas, él se gira indiferente, con una media sonrisa casi boloñesa. Una bonita pluma tiene en el sombrero de terciopelo morado y una fina espada le cuelga de la cadera. Las piernas nerviosas se ven más allá del taburete, como si estuvieran descansando, tras una carrera, tras una pelea.]

Gadda reproduce verbalmente los gestos, las posturas y las miradas así como las expresiones faciales de los personajes, confiriendo a su descripción el ritmo narrativo que rige la composición de la escena. Al mismo tiempo, sabe recrear el estatismo, la rigidez con la que Caravaggio pinta sus figuras: por un lado el Cristo que exige, cuyo cuello torcido y el brazo tendido quedan destacados de la oscuridad por la fuerte proyección de la luz; y por otro, el joven de espaldas, cuya imagen se descompone en la serie de detalles figurativos que entran progresivamente en el campo de visión del espectador y sintácticamente quedan ordenados por yuxtaposición: la mirada desafiante, las mejillas y la sonrisa, la pluma del sombrero, la espada y las piernas. Los sustantivos se combinan con unos adjetivos calificativos referidos a las tonalidades vivas del rojo (mejillas) y del violeta (sombrero) así como a la forma de la espada y al estado de las piernas, con el resultado de evocar la carga de sensualidad y el sentimiento amenazador que inspiran el joven. El escritor consigue crear una imagen de cariz impresionista con un intenso efecto visual, además de reinterpretar los valores descriptivos y narrativos del luminismo y cromatismo de los que se sirve Caravaggio para, a través de su análisis directo de la realidad, dramatizar las expresiones de las figuras y otorgarles una nueva calidad plástica. Al grupo icónico de los jóvenes, representación del ardor juvenil y sensual, Gadda vuelve en otros escritos como, por ejemplo, en Accoppiamenti giudiziosi, donde se lee: «i piumati bravi la cui adolescenza risfolgora e le sottili spade posano, alla tavola del gioco, nella tela segreta del Caravaggio» (2007:843) [los emplumados "bravi» cuya adolescencia reluce y que las finas espadas deponen, en la mesa de juego, en el lienzo secreto del Caravaggio]. Las pinturas de Caravaggio a menudo parecen remitirse a algo fuera del cuadro. Gadda recoge esta sugerencia al traer a colación del fragmento descriptivo, el relato de un suceso que se desarrolla en el exterior del espacio cerrado de la taberna. $\mathrm{Al}$ amparo de las sombras del humilde barrio popular en los que campan a sus anchas los equívocos compañeros de Mateo, jóvenes dispuestos a cometer toda clase de fechoría, se produce un suceso cruento: 
Nei vicoli, sotto gli archi dei passaggi, passano ridendo i micheletti della ronda e qualche puttana si rimpiatta, inseguita da sgangherate risate. Poi, quando la ronda si perde con una cadenza lontana (...) si può chieder conto, de' suoi diportamenti, a uno che passerà. Una spallata. E perché, e per come. Le voci son basse e concitate. Ma qualche finestra si apre e donne in camicia si danno a invocare la Madonna. Il soldo comanda e la spada lavora. (2008:682) [En las callejuelas, debajo de los arcos de los pasajes, pasan riéndose los soldados de la ronda y alguna puta se aparta, seguida por una risa desquiciada. Luego, cuando la ronda se pierde con cadencia lejana (...) se pueden pedir explicaciones, de sus acciones, a uno que pasará. Un empujón. Y por qué, y cómo. Las voces son bajas y apresuradas. Pero alguna ventana se abre y mujeres en camisón empiezan a invocar a la Virgen. El dinero manda y la espada trabaja.]

Y la luna que está en lo alto del cielo "fa diagonali di ombra e di biancore sui quadri delle case e sui tetti» [hace diagonales de sombra y de blancura en los cuadrados de las casas y sobre los tejados], sin llegar a alumbrar el escenario en el que se está consumando el brutal acto sanguinario. Gadda tuvo que quedar fascinado por ese haz de luz que, en Vocación, atraviesa diagonalmente la composición otorgándole profundidad al cuadro: generado desde un indeterminado punto interno se acerca a la superficie según la diagonal del cubo. En la pintura, una luz cegadora, de origen divino, supera en luminosidad a la del día, que debería traslucir desde una ventana. La luz artificial traza una línea que resalta la ortogonal imaginaria que, partiendo del índice perentoriamente apuntado de Jesús, gesto repetido por su acompañante, orienta la mirada del espectador hacia un Mateo desconcertado. Sin embargo, no se detiene en el apóstol sino que, como subraya Longhi, "fruga viso e spalle del giocatore a capotavola che vorrebbe immergersi nell'ombra lurida della propria perplessità» (72) [rebusca rostro y hombros del jugador sentado al otro lado de la mesa que querría sumergirse en la sombra corrupta de su propia perplejidad]. En el texto de Gadda, la luz "geométrica», que en el cuadro separa lo sacro de lo profano, queda asimilada gráficamente a la fría luz emanada por Luna. Ello, sin embargo, no implica una visión pesimista y laica, en cuanto seguidamente Gadda apela a otra luz, a «la luce di tutti», a la porción de luz que «deve arrivare ad ognuno» [tiene que llegar a todos] por el mero hecho de existir, de haber nacido. ${ }^{13}$ Puesto que no es cometido del presente estudio profundizar en ello, es oportuno reseńar, sin embargo, la poderosa sugestión que ejerció sobre Gadda esta luz, no sólo en cuanto vector con significación metafísica, sino como elemento de ejecución técnica, ya que es posible encontrarla en la construcción de numerosas escenas de la novela Aprendizaje, como se puede comprobar en algunos de los ejemplos referidos más adelante.

Si el luminismo y el nuevo sistema cromático tenían gran protagonismo en la recreación literaria de la Vocación, hay otro elemento que la sensibilidad del ojo de Gadda al fenómeno figurativo sabe detectar y reinterpretar magistralmente, a la vez que permanece en su sistema imaginativo; a saber, el espacio y la manera en la que los sujetos pintados se distribuyen relacionándose con él. A este propósito, el crítico de arte Walter Friedländer afirmaba que:

El nuevo sistema cromático de Caravaggio, que refuerza la pronunciada dirección de avance de la estructura composicional, trae lo sobrenatural a la realidad del mundo cotidiano. Pero al mismo tiempo la luz milagrosa separa lo sagrado de lo mundano. Hay, pues, una especie de antinomia en las obras maduras de Caravaggio: por su disposición las figuras y objetos se 
adelantan casi palpablemente a la percepción inmediata del espectador, en tanto que la luz intensa e inexplicable los inviste de una sublimidad (...) Aunque dotados de recia corporeidad, los objetos están al mismo tiempo encantados, como bajo un hechizo mágico. (46)

En el ensayo "Il pasticciaccio» (Letteratura, 1957) se halla otro fragmento fundamental para el presente análisis. Al hilo de las cavilaciones acerca de la adhesión del arte a la realidad sin menoscabo de su función heurística, Gadda evoca el cuadro de Caravaggio, Conversión de San Pablo (Figura 2), en cuanto ejemplo magistral de estilo representativo que logra vehicular la visión directa e inmediata de un acontecimiento real a la vez que su significación. Así se describe en términos figurativos el lienzo custodiado en la Iglesia de Santa Maria del Popolo:

Paolo atterrato dalla folgore: raccorciato, nanificato a terra dalle leggi inesorabili della prospettiva. Tutto il quadro occupato dalla Bestia (...) La Bestia immobile, insenziente, davanti al fulgurare della Luce: il negoziante di tappeti sbattuto a terra, sulla strada che lo dilungava dal Verbo: che lo portava all'emporio, a Damasco: richiamato nella direzione opposta, la giusta. $(2008,510)$ [Pablo postrado por el rayo: acortado, empequeñecido contra el suelo por las leyes inexorables de la perspectiva. Todo el cuadro ocupado por la Bestia (...) La Bestia inmóvil, insensible, delante del resplandor de la Luz: el mercader de alfombras tirado al suelo, en la vía que lo alejaba del Verbo: que lo llevaba al emporio, a Damasco: llamado en la dirección opuesta, la correcta.]

Con sagacidad, Gadda capta el punto de originalidad con el que se representa la llamada del apóstol. Caravaggio, pues, inmortaliza el suceso en el instante exacto en el que acaba de acontecer: el evangelista se halla en el suelo, recién caído de su montura, ciego y aterrado, casi aplastado entre la masa imponente del animal que se cierne sobre él y el espacio del espectador. El santo extiende hacia arriba los brazos para acoger la fe, aún cegado por la luz divina que irrumpe e incide sobre Saulo y el caballo que siguen dos trayectorias diferentes. Una vez más el efecto lumínico logrado por el pintor le permite separar, de forma casi antinómica, lo sacro de lo profano. El hombre, con su postura, deja patente su rendición a la llamada imperiosa de Dios mientras que el animal, la «bestia insenziente», no tiene conciencia de lo acontecido y parece representar una cotidianidad tan sólo rozada por lo sobrenatural. En su evocación del cuadro, el escritor milanés centra su atención una vez más en los medios pictóricos utilizados por Caravaggio, por un lado, la luz y, por otro, la racionalización casi geométrica en la disposición de las figuras, con el fin de poder transmitir el alto grado de intensidad expresiva alcanzado por el original pintado. En lo referente al peculiar efecto proxémico logrado por la composición de la escena y tan eficazmente comunicado por Gadda, aclara Raimondi: «a questo punto lo spazio non è più semplice contenitore, ma diventa soggetto attivo nel quadro, diventa una specie di forza, reagisce sui corpi. Pensino a certi gesti di Caravaggio: il gesto è dentro lo spazio e lo spazio esiste e dialoga con il gesto, quindi c'è una sorta di dinamicità del rapporto spaziale» (2003:93) [en este punto el espacio ya no es un simple contenedor, sino que se convierte en un sujeto activo del cuadro, se convierte en una especie de fuerza, actúa sobre los cuerpos. Sólo hay que considerar ciertos gestos de Caravaggio: el gesto está dentro del espacio y el espacio existe y dialoga con el gesto, por lo que se crea una suerte de dinamismo en la relación espacial].

Los textos estudiados en su cotejo con la obra representan a su vez un intertexto de la escritura de Gadda. Al estilo revolucionario de Caravaggio, pero también a su 
personal lectura de la imagen, el autor parece remitirse o buscar inspiración en el proceso creativo e imaginativo. De ahí que el estímulo figurativo coagule en las páginas de su novela Aprendizaje del dolor al forjar unas secuencias. Como en los cuadros de Caravaggio, en estos pasajes parece como si toda acción se hubiera suspendido; sin embargo, los personajes inmóviles, fijos en sus posturas, elocuentes en sus gestos y facciones, despiertan en el lector la emoción intensa que domina su interioridad psíquica. No es casual, de hecho, que se trate justamente de fragmentos que forman parte de los principales núcleos de significado de las obras, como se verá en ellos se vislumbran significaciones profundas más allá de la apariencia, de la superficie de las cosas. En el análisis textual de una de las mayores novelas de Gadda se hará hincapié tanto en la presencia de medios de ejecución pictórica (los contrastes de luz y sombra, el uso de espacios limitados y el cuidado en la disposición de objetos y figuras humanas, las posturas de los personajes), como en el uso de elementos iconográficos en la construcción de escenas de las que se desprende un intenso pathos.

En esa dolorosa autobiografía ficcional que es Aprendizaje del dolor, los efectos lumínicos de luz y sombra afectan en gran medida las representaciones de los dos protagonistas. De esta forma se puede comprobar cómo Gadda construye una escena en términos figurativos con el fin de evocar las emociones intensas de su relación de amor y odio. Se trata, a su vez, de una variación sobre un motivo ya utilizado por el autor en Racconto. Aquí se había bosquejado el interior de una habitación según la técnica del cuadro en el cuadro, en el que el círculo de luz de un candil alumbra la reproducción de la Vocación de San Mateo, mientras la oscuridad protege al protagonista, Grifonetto, identificado con uno de los compañeros de San Mateo, el que está sentado de espaldas y mira, sin entender la orden de Jesús. En la novela, en cambio, la reiteración icónica así como el claroscuro sirven para configurar el espacio cerrado de la cocina en la que la madre sirve la cena al hijo recién llegado de un viaje de trabajo. En Aprendizaje, además es la Madre la que se queda en la sombra, temblorosa en espera de un posible gesto de arrebato de su hijo. El cono de luz blanca, «lumignolo cosí stanco e dimesso», ilumina a duras penas la mesa en la que hay un tazón humeante. Los objetos contenidos en la casa se erigen como símbolo del cuidado maternal, con respecto a los cuales Gonzalo manifiesta un sordo resentimiento, causándole incluso arrebatos de ira ("gli parve essere tutto quello che la madre concedeva» (1987:318) [le pareció ser todo lo que la madre le concedia]:

quando discese, con un libro, la zuppa sembró attenderlo in tavola, al suo posto, nel cerchio della lucernetta a petrolio: dal di cui tenue dominio il fumo della scodella vaporava a disperdersi nella oscurità (...) La mamma, ora, dopo essere uscita e rientrata più volte, attendeva ella pure all'impiedi, quasi tremando, le mani ricongiunte sul grembo, che il figliuolo si mettesse a tavola (...) dentro il buio della cucina. $(318,336)$

[cuando bajó, con un libro, la sopa pareció esperarlo en la mesa, en su lugar, en el círculo del pequeño candil de aceite: desde cuyo dominio el humo del tazón evaporaba dispersándose en la oscuridad (...) Su madre, ahora, tras idas y venidas, esperaba también ella de pie, casi temblando, sus manos entrelazadas en el regazo, que su hijo se sentara a la mesa (...) dentro de la oscuridad de la cocina.]

Al presente concreto de esta escena, el hilo de la narración se reconecta al cabo de cada una de las analepsis referidas, mediante discurso indirecto, por la anciana o el hijo, casi para remarcar el nudo de dolor en su relación y en sus respectivas 
vidas. El hijo, aquejado por el «mal de vivir», apartado de la «sana vida de los demás y de la luz» está condenado a la negatividad, a la oscuridad, mientras que sobre la Madre pesa un pasado lleno de penas. La casa se convierte en el traslado de la neurosis de Gonzalo, portadora de una violencia avasalladora, ciega hacia toda piedad humana, a la que sucumbirá la anciana, como se ve en una de las secuencias clave de la novela: la madre sola deambula por las habitaciones entablando un diálogo mudo con las sombras de su pasado. La luz, como medio técnico además de metafísico, juega un rol fundamental. La escena se recompone alrededor de la antitesis creada por la luz veraniega que inunda el exterior y se combina de forma sinestética con el ruido emitido por las cigarras, para formar la isotopía de la vida, y con la sombra y el silencio que envuelven el espacio interior así como la figura de la madre casi acechándola con su carga de dolor y de muerte. Los cegadores rayos de sol inciden alumbrándolo el desalińado y pobre vestido de la anciana, desvelando su exclusión de la luz, su lejanía de la plenitud de la vida:

\begin{abstract}
Vagava nella casa: e talora dischiudeva le gelosie d'una finestra, che il sole entrasse, nella grande stanza. (...) Ma che cosa era il sole? Quale giorno portava? sopra i latrati del buio (...) la luce allora incontrava le sue vesti dimesse, quasi povere: i piccoli ripieghi di cui aveva dovuto mendicare, resistendo al pianto, l'abito umiliato della vecchiezza (...) vagava nella casa (...) dalla cucina senza più fuoco alle stanze senza più voci: occupate da poche mosche. E intorno alla casa vedeva ancora la campagna, il sole. (258)

[Deambulaba en la casa: y a veces entreabría las celosías de una ventana, para que el sol entrara, en la habitación tan amplia (...) Pero, ¿qué era el sol? ¿Qué día era? por encima de los ladridos de la oscuridad (...) la luz encontraba su ropa descuidada, casi pobre: los pequeños expedientes con los que habia tendido que mendigar, deteniendo el llanto, el vestido humillado de su vejez (...) deambulaba en la casa (...) desde la cocina ya sin fuego hasta los cuartos ya sin voces: ocupadas por pocas moscas. Y alrededor de la casa todavía veía el campo, el sol.]
\end{abstract}

El medio pictórico de la luz se convierte en dispositivo retórico que contribuye a esbozar una imagen creada por la palabra vívida, dotada de inmediatez y de fuerza dramática, a la vez que sugiere al ojo del lector la acción psíquica que tiene lugar en la interioridad del personaje. Unas páginas más adelante, la madre protagoniza de nuevo una secuencia representada en términos figurativos, en la que, además, se traslucen unos nexos icónicos intertextuales con los cuadros de Caravaggio, comentados antes. Durante una tormenta nocturna, el estrépito de los truenos, el aullido del viento y el estruendo de la lluvia infunden en la madre un miedo incontrolado que la obliga a buscar refugio en el hueco oscuro de debajo de la escalera. Lejos de estar a salvo, la casa vuelve a revelarse como el contenedor de su dolor, de la ausencia de toda caridad humana. En la débil luz de una cerilla con la que intenta encender una vela, la mujer percibe la temible visión de un símbolo del mal, «nel giallore (...) ecco ulteriormente fuggitiva una scheggia di tenebra, orrenda (...) il nero dello scorpione» (264) [en la luz amarillenta (...) aparece también fugitiva una esquirla de tinieblas, horrenda (...) lo negro del escorpión]. El sentimiento de terror que le embarga las fuerzas, obligándola a quedarse inmóvil y a asumir una postura que parece recalcar la de Saulo de Caravaggio: «si raccolse allora, chiusi gli occhi, nella sua solitudine ultima: levando il capo, come chi conosce vana ogni implorazione di bontà» (264) [entonces se encogió, con los ojos cerrados, en su soledad última: levantando la cabeza, como el que sabe que es vana 
toda imploración de bondad]. A continuación, como si de una rápida secuencia de fotogramas cinematográficos se tratara, la luz eléctrica de los relámpagos que filtra desde lo alto de las celosías cerradas, deja ver que «lo scorpione, risveglio, aveva proceduto, come di lato, come a raggirarla, ed ella, tremando, aveva retroceduto dentro il suo solo essere, distendendo una mano diaccia e stanca, come a volerlo arrestare» (268) [el escorpión, reactivado, habia avanzado, como de lado, como para engañarla, y ella, temblando, habia retrocedido dentro de su solitario ser, extendiendo una mano gélida y cansada, como si quisiera detenerlo]. Pese a las modificaciones derivadas por el proceso de contextualización de la cita figurativa, es palpable la sugestión ejercida por la lección de perspectiva mediante la cual el pintor escorza de forma ortogonal el cuerpo de San Pablo, reduciéndolo y aplastándolo, la que no sólo sugiere a Gadda cómo disponer los objetos con la ayuda del claroscuro, sino que le indica además cómo explotar las relaciones establecidas entre estos elementos en el espacio cerrado para cargar la escena de fuerza dramática. Por otro lado, como se decía, algunos elementos figurativos parecen apuntar a la presencia de otra matriz figurativa. La ventana en alto, la estrechez del lugar, las alusiones a algo fuera del cuadro remiten a la Vocación de San Mateo; más bien a la lectura interpretativa del cuadro ofrecida por Gadda en su "Apologia manzoniana». El fragmento descriptivo evoca el desencadenarse de la borrasca con una simultaneidad de datos sonoros, cinéticos y visivos de matriz futurista y se cierra con una similitud que pretende personificar un agente atmosférico y lo hace a la manera de Caravaggio: «tutto il cielo si disfrenava alle folgori, come nel guasto e nelle rapine un capitanaccio dei lanzi a gozzovigliare tra sinistre luci e spari» (262) [todo el cielo se desenfrenaba con los relámpagos, como en la destrucción y en el robo, un capitán de mercenarios monta su juerga entre luces siniestras y disparos.${ }^{14}$ Lo que aquí emerge con más evidencia es la coincidencia temática con la identificación entre los jóvenes compańeros de Leví con los «bravi» del siglo diecisiete de la novela de Manzoni. El nexo intertextual interno queda corroborado también por la reiteración de la palabra «vento" y su transposición simbólica a la muerte o a instrumento de muerte. Se lee en el texto después del pasaje citado: «il vento che le aveva rapito il figlio verso smemorati cipressi, ad ogni finestra pareva cercare anche lei» (262) [el viento que le habia arrebatado a un hijo hacia los cipreses sin memoria, en cada ventana parecía que la estaba buscando a ella también]. Para encontrar el término usado como traslado figurado hay que remontarse a la primera versión de la "Apologia», es decir la nota compositiva del Racconto, en la que se lee: «il vento del caso trascina in un corso di miserie senza nome» (2008:590) [el viento del azar arrastra a lo largo de miserias sin nombre].

Pasado ya el temporal, durante la noche, unos improvisados vigilantes se percatan de algo raro en la casa y, al explorarla, encuentran a la madre en su cama moribunda a causa de un violento golpe en la cabeza. Pese a ser atendida por un médico, la mujer expira. La imagen de la difunta parece remitir a un cuadro tan conocido como polémico de Caravaggio, La muerte de la Virgen (Figura 3). El autor no hace mención directa a esta obra en sus escritos. Sin embargo, por su familiaridad con la producción del pintor lombardo, no pudo no sentirse fascinado por el lienzo que cerró el periodo romano de Caravaggio antes de su precipitada huida. Pintado para la Iglesia Santa Maria della Scala entre 1605 y 1606, el cuadro fue rechazado por su comitente y vendido al Duque de Mantua sin que antes despertase un interés muy vivo en los artistas de la época. Se puede plantear la hipótesis, por lo 
tanto, de que el revolucionario e incomprendido maestro ofreciera una vez más un equivalente pictórico a la imaginación de Gadda. Así la relajación típica de los muertos retratada con tanto realismo por el pintor en La muerte de la Virgen le sugeriría al autor la asimilación de la muerte a un estado de extremo cansancio, de postración, pero en el que todavía el cuerpo y las facciones del rostro se muestran como el simulacro de un alma noble. Pese al ultraje infligido por el acto de violencia inaudita, la madre mantiene, casi renovada, la distinción y la magnanimidad que la caracterizaban de viva y, a quien la observa ya de difunta, también se lo recuerda. Tendida en la cama, como la virgen del Caravaggio, su rostro se presenta «nella stanchezza senza soccorso in cui il povero volto si dovette raccogliere tumefatto, come in un estremo ricupero della sua dignità, parve a tutti di leggere la parola terribile della morte e la sovrana coscienza della impossibilità di dire: Io» (472) [en el cansancio sin socorro en el que el pobre rostro se encogía tumefacto, como en una extrema recuperación de su dignidad, les pareció a todos leer la palabra terrible de la muerte y la soberana conciencia de la imposibilidad de decir: Yo]. Este motivo temático queda reiterado en términos figurativos similares en la descripción del rostro de otro personaje femenino asesinado a mano de desconocidos, la señora Liliana en el Zafarrancho aquel de via Merulana: «Oh, gli occhi! Dove, chi guardavano? Il volto!... Oh, era sgraffiata, poverina! Fin sotto un occhio, sur naso!... Oh, quel viso! Com'era stanco, stanco, povera Liliana, quel capo, nel limbo, che l'avvolgeva, dei capelli, fili tuttavia operosi della carità. Affilato nel pallore, il volto: sfinito, emaciato dalla situazione atroce della morte (2007:58). [;Oh, los ojos! ¿Dónde, a quién miraban? ;El rostro!... ;Oh, estaba arañada, la pobre! ;Hasta debajo de un ojo, en la nariz!.... ;Oh, aquel rostro! ; Qué cansada estaba, cansada, pobre Liliana, aquella cabeza, en el limbo, que la envolvía, del pelo, hilos aún activos de la caridad! Afilado y pálido, el rostro: exhausto, marcado por la situación atroz de la muerte].

A modo de conclusión, y a tenor de lo dicho, ello dejaría patente la profundidad de la huella dejada por Caravaggio, así como la lectura única de sus cuadros, en el sistema imaginativo de Gadda. Se trata de una inspiración pictórica que actúa en la escritura creativa del autor y de la que el escritor tiene plena conciencia, como se ha podido comprobar en el análisis de las lúcidas manipulaciones verbales de los datos figurativos que se hallan en algunos de sus textos críticos. La sensibilidad del ojo gaddiano queda magistralmente reflejada tanto en la ductilidad del material verbal como en los recursos estilísticos mediante los cuales el escritor logra dar forma plástica a sus mundos literarios. En sus páginas los elementos iconográficos y escuetamente narrativos se mezclan con los medios pictóricos como la luz, la sombra, el cromatismo, la disposición de los elementos en el espacio con efectos de intenso dramatismo. 


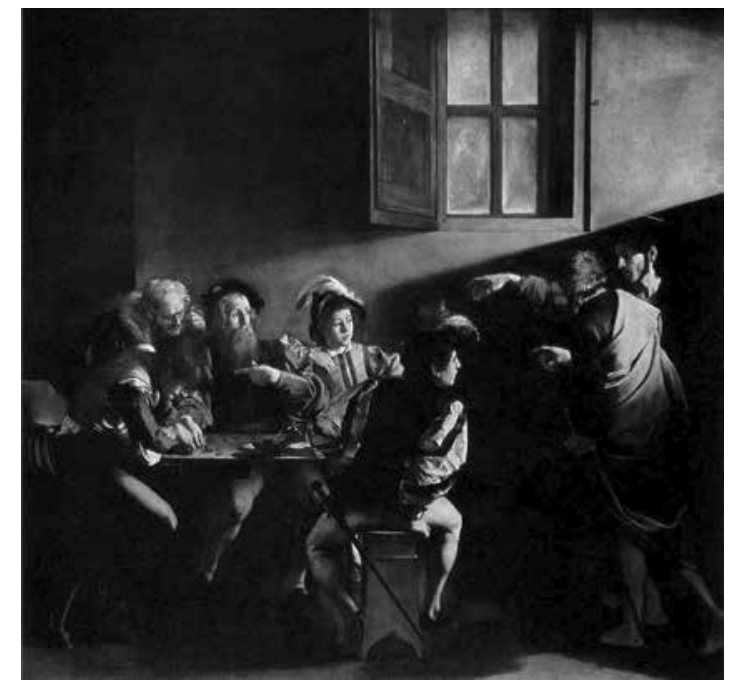

Figura 1.

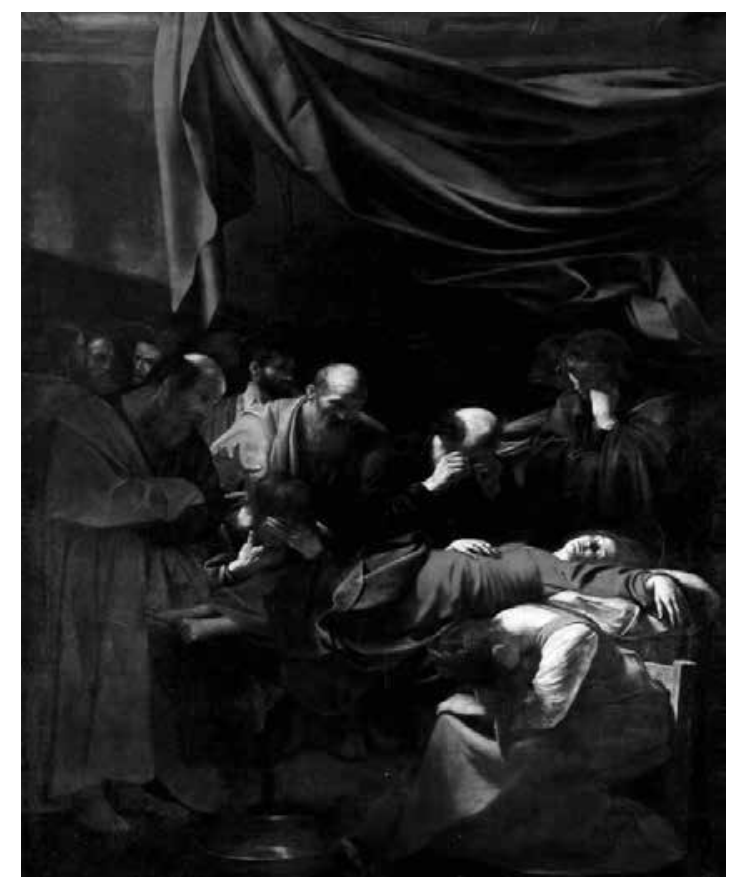

Figura 3.

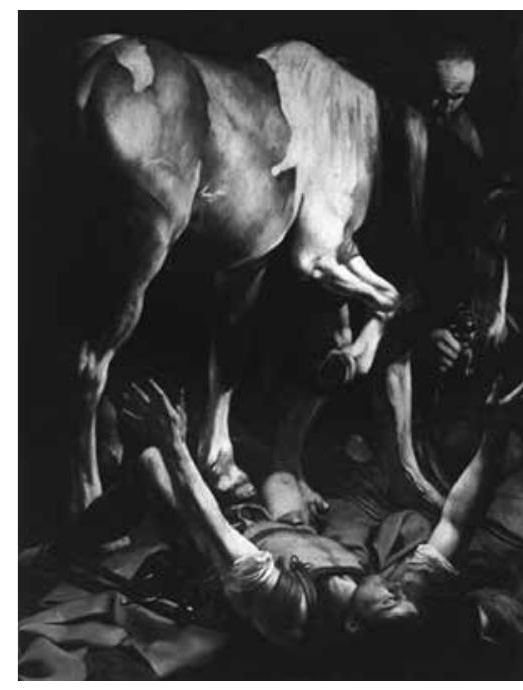

Figura 2. 


\section{Notas}

${ }^{1}$ A este respecto es oportuno señalar, por un lado, la contemporaneidad de la línea interpretativa de Roberto Longhi. En los primeros años del siglo $\mathrm{XX}$, el crítico de arte investiga el repertorio iconológico sobre el que se plasma la escritura de Alessandro Manzoni: la pintura lombarda del siglo XVI. Algunos fragmentos significativos se pueden leer en sus primeros artículos publicados, ahora recogidos en Roberto Longhi (1980) Scritti giovanili. Firenze: Sansoni. Por otro lado, para profundizar en la lectura gaddiana de Manzoni al hilo del binomio del novelista con Caravaggio, se remite al magistral, y todavía válido, estudio de Gianfranco Contini «Premessa su Gadda manzonista» publicado en L'Approdo Letterario (1973).

${ }^{2}$ Sobre el concepto de écfrasis se remite al excursus esbozado por Tomás Monterrey en el que se enlazan las posturas que, actualmente, configuran el estado de la cuestión acerca del estudio de los engarces entre artes visuales y literatura. Entre los autores que ofrecen nuevos modelos téoricos el crítico recoge a Krieger, Plett, Pfister, Robillard, Weisstein, Yacobi (Monterrey).

${ }^{3}$ Las fechas a las que se hace referencia remiten a las primeras publicaciones en revista de la novela. El aprendizaje del dolor se publica en volumen en 1963, y le siguen las ediciones revisadas y ampliadas de 1970 y 1987.

${ }^{4}$ Es útil recordar que la peculiar concepción de la literatura en cuanto instrumento heurístico de lo real, que se delinea en las notas compositivas contenidas en el Cabier d'ètudes del Racconto, arraiga en la tradición de la ilustración lombarda y sus epígonos decimonónicos (Carlo Cattaneo, entre otros), a la que se debe la ética del respeto por el dato derivado de la observación empírica (Raimondi:135-137).

${ }^{5} \mathrm{~N}$. del A.: todas las traducciones del italiano son mías.

${ }^{6}$ El término Barroco es utilizado por Gadda en una acepción personal que difiere de la categoría historiográfica general. Sin embargo, se remite al repertorio iconológico manzoniano que, investigado por Roberto Longhi, está formado por la obra pictórica de autores del siglo XVI como Lorenzo Lotto.

${ }^{7}$ Se trata del pintor español José de Ribera, también conocido con su nombre italianizante Giuseppe Ribera y el mote «lo spagnoletto». Fue representante en Italia del estilo tenebrista y cercano a Caravaggio.

${ }^{8}$ Se lee en la "Apologia», «Michelangiolo Amerighi veste da bravi i compagni di gioco di San Matteo» (Gadda, 2008:681) [Michelangiolo Amorigi viste de pillos (bravi) a los compañeros de juegos de San Mateo]. Explica Corrado Bologna (1998): «Proiettando con paradossale inversione cronologica i "bravi" manzoniani nel quadro caravaggesco essa penetrava, grazie a inattesi e inediti strumenti d'indagine, nel cuore di un libro troppo a lungo presentato come un classico della pacificazione provvidenzialistica e della classicità rappresentativa: e così riusciva a cogliere la vitalità del barocco (e del realismo o naturalismo barocco) di cui era profondamente intriso quell'immaginario iconologico" [Proyectando con paradójica inversión cronológica los «bravi» de Manzoni en el cuadro de Caravaggio se penetraría, gracias a las inusuales e inéditas herramientas de investigación, 
en el corazón de un libro que durante demasiado tiempo fue presentado como un clásico de la pacificación providencial y del clasicismo canónico: y asi se lograría singularizar la vitalidad del Barroco (y del realismo o naturalismo barroco) del que ese imaginario iconológico estaba impregnado].

${ }^{9}$ Representativo de esta etapa cultural fue el ensayo de Antonio Borgese, Tempo di edificare (1923), en el que el autor recopila un grupo canónico de representantes italianos de la narración realista.

${ }^{10}$ En lo que respecta a Caravaggio pesaba sobre su obra, desde hace dos siglos, el lastre de la valoración negativa formulada por sus mismos biógrafos, Bellori y Baglione.

${ }^{11}$ Vocación de San Mateo (Iglesia San Luigi dei Francesi, Capilla Contarelli, Roma, 1599-1600).

${ }^{12}$ Conversión de San Pablo (Iglesia Santa María del Popolo, Roma, 1601-1602).

${ }^{13}$ A este respecto Gadda desarrolla unas enredadas cavilaciones que forman parte de su visión de la humanidad y de la historia, y por las que la luz, contrapuesta a la oscuridad y a la penumbra, se convierte en un traslado figurado que remite tanto al ideal principio ético que debería regular la esfera de lo privado y de lo social, como a la incontenible fuerza vital inherente al perpetuarse biológico de la especie.

${ }^{14}$ Se trata de la clave de lectura ofrecida por Emilio Manzotti en la nota 83 de página 262 de la edición crítica y anotada del Aprendizaje del dolor de la que aquí se cita.

\section{Referencias bibliográficas}

Bologna, Corrado (1998). «Il filo della storia. "Tessitura” della trama e "ritmica" del tempo narrativo fra Manzoni e Gadda». Critica del testo, (1), 345-406. Consultado el 20 de febrero de 2014 en http://www.gadda. ed.ac.uk/Pages/resources/archive/influences/bolognfilo.php.

Calvesi, Maurizio (1990). Nella realtà di Caravaggio. Torino: Einaudi.

Contini, Gianfranco (1988). «Premessa su Gadda manzonista». Ultimi esercizi ed elzeviri (1968-1987). Torino: Einaudi, 151-153.

Friedländer, Walter (1955). Estudios sobre Caravaggio. Madrid: Alianza, 1995.

Gadda, Carlo Emilio (1987). La cognizione del dolore. Manzotti, Emilio (ed.). Torino: Einaudi.

(2007). Pinotti, Giorgio; Isella, Dante; Rodondi, Raffaella (eds.). Romanzi e racconti II. Milano: Garzanti.

(2008). «Il pasticciaccio» y «Apologia manzoniana». Orlando, Liliana; Martignoni, Clelia; Isella, Dante (eds.). Saggi, Giornali, Favole e altri scritti I. Milano: Garzanti, 506-511 y 679-687.

(2009). Racconto italiano di ignoto del Novecento (Cabier d'ètudes). Silvestri, Andrea; Vella, Claudio; Isella, Dante; Italia, Paola; Pinotti, Giorgio (ed.). Scritti vari e postumi. Milano: Garzanti. 
Lipparini, Micaela (1994). Le metafore del vero. Percezione e deformazione figurativa in Carlo Emilio Gadda. Pisa: Pacini Editore.

Longhi, Roberto (1980). Scritti giovanili. Firenze: Sansoni (1982). Caravaggio. Roma: Editori Riuniti.

Monterrey, Tómas (2000). «La esencia de la écfrasis». El retrato literario: tempestades y naufragios, escritura y reelaboración: actas del XII Simposio de la Sociedad Española de Literatura General y Comparada. Huelva: Universidad de Huelva, 515-522.

Pacciarotti, Giuseppe (2000). La pintura barroca en Italia. Madrid: Ismo. Raimondi, Ezio (1990). «Nella luce di Caravaggio: fra Gadda e Longhi». Barocco moderno: Roberto Longhi e Carlo Emilio Gadda. Milano: Mondadori, 133-168, 2003.

\section{Garosi, Linda}

«Visiones del Caravaggio romano entre las páginas de 